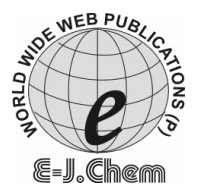

http://www.e-journals.net
CODEN ECJHAO

E-Journal of Chemistry

Vol. 3, No.1, pp 49-59, January 2006

\title{
Removal of Lead Ion from Aqueous Solutions Using Sawdust Coated by Polyaniline
}

\author{
R. ANSARI * and F. RAOFIE \\ Chemistry Department, \\ Guilan University, \\ Rasht, Iran, POB: 41335-1914 \\ E-mail: ransari@guilan.ac.ir
}

Received 24 October 2005; Accepted 23 January 2006

\begin{abstract}
Polyaniline was synthesized chemically, coated on sawdust via cast method in the form of emeraldine base (EB) from formic acid as solvent, and used as an adsorbent for removal of lead ion or from aqueous solution. The effects of some important chemical and physical factors in removal efficiency have also been investigated. Among the different parameters, the effect of $\mathrm{pH}$ was the most prominent. It was found that metal uptake is occurred under neutral or slightly alkaline conditions, while under relatively strong acidic media, the sorption of the investigated metal ions was negligible and desorption is a predominant process. It was found that undoped PANi (EB form) coated on polar substrates such as sawdust (SD) can be used as an effective adsorbent for removal of heavy metal ions in water and wastewater treatments. All the previous investigations and applications take advantage of the electrical conductivity (metallic), electrochemical (redox activity) and electrochromic properties of the polyaniline. While; in this research, we have taken advantage of the chelating properties of PANi for metal sorption.
\end{abstract}

Key words: Adsorption, polyaniline, sawdust, lead ion, desorption

\section{Introduction}

Heavy metal ions are highly toxic for animals and human beings. Environmental contamination by heavy metals is a widespread problem, with sources of pollution arising from industrial activities. These metals are of significant importance as they are nonbiodegradable and once released into the environment, they can only be diluted or transformed, not destroyed ${ }^{1}$. 
Heavy metal ions pose a series risk to the environment and endanger public health and the environment. Therefore, they should be removed from water and wastewaters before discharge. The origin of the heavy metal contamination of waters lies in the illegal disposal of industrial effluents, corrosion of the metal pipes used to carry water. Adsorption by activated carbons and ion exchange resins has been widely studied as an effective technique for removing toxic heavy metals such as $\mathrm{Hg}^{+2}, \mathrm{Cd}^{+2}$, and $\mathrm{Pb}^{+2}$ from aqueous solutions ${ }^{2-4}$. However; these methods suffer from the complete elimination of heavy metals at very low concentrations. So, many investigators are directed towards chemical modifying activated carbon (AC), or other adsorbent surfaces (synthetic or biomaterials), synthesis cation exchanger resins with a chelating group such as iminodiacetic acid and microbial methods to increase removal efficiency of heavy metals ions from aqueous solutions ${ }^{5,6}$. Adsorption of metals by modified AC can be correlated to its both physical and chemical nature and metal sorption by AC is mostly due to the surface complex formation between the metal ions and the acidic surface functional groups ${ }^{7,8}$. The removal efficiency is influenced by many parameters such as surface area and other physical properties of the adsorbent, adsorbate concentration, solution $\mathrm{pH}$, sorbent dosage and its modification procedure. Polyaniline is a well-known conducting/electroactive polymer. It is one of the most potentially useful conducting polymers and has received considerable attention in recent years by many investigators ${ }^{9-16}$.

Recently some investigators directed their research toward application of conducting polymers (e.g. polypyrrole, polyaniline) for water softening and removal of heavy metal ions from aqueous solutions ${ }^{7}$. The principle is based on the switchable ion exchange properties of conducting polymers. The application of electrochemically controlled ion-exchange for water and wastewater treatment in order to removing of heavy metals offers certain ecological and economic advantages because its electrochemical regeneration is accompanied by without any chemical additives.

The unique electrical/electrochemical properties of PANi, have led to use this polymer in various applications such as sensors, rechargeable batteries, light emitting diodes, smart windows, non linear optical and energy storage devices, anti-static and anti-corrosion coating materials ${ }^{16,18}$. Polyaniline can be easily synthesised either chemically or electrochemically from acidic aqueous solutions. Chemical polymerisation of aniline in aqueous acidic media (bronsted acid) can be simply performed using of oxidising agents such as $(\mathrm{NH})_{4} \mathrm{~S}_{2} \mathrm{O}_{8}, \mathrm{KIO}_{3}$ and $\mathrm{K}_{2} \mathrm{Cr}_{2} \mathrm{O}_{7}$. Chemical structure of PANi can be shown as in Figure 1.

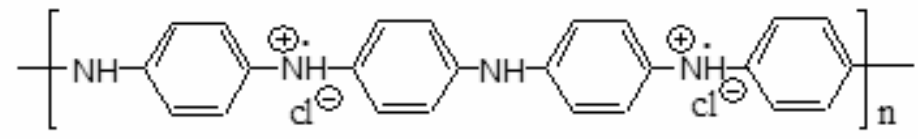

Figure 1 Chemical structure of polyaniline as synthesized and acid doped(PANi/HCl)

All of the previously reported of polyaniline conducting polymers are based on its interesting and unique electrical conductivity (metallic) and electoactivity. However; this paper deals with the new potential application of polyaniline as a cation exchanger material useable for environmental protection in water and wastewater treatment technology. Based on the polymer structure and its dependence on the nature of dopant acid and $\mathrm{pH}$, a range of chemical processes such as ion exchange, complex formation, precipitation and even enzyme reactions can be carried out on polymer surface. This finding should be very 
important and promising for application of polyaniline in future water and wastewater treatment technology.

\section{Experimental}

\section{Reagents}

The entire chemicals used were of analytical reagents (AR grade). All solutions were prepared in Milli-Q water. Aniline (Merck) was purified by vacuum distillation and stored in freeze before polymerization.

\section{Adsorption experiment and preparation of PANi/SD adsorbent}

Polyaniline was synthesized chemically as described previously using potassium dichromate as oxidant. After purification and changing it into emeraldine base (EB) by treatment with a dilute ammonia solution $(0.5 \mathrm{M})$ or $\mathrm{NaOH} 0.2 \mathrm{M}$, it was dried and then dissolved in concentrated formic acid (\%88). A layer of PANi coated on sawdust (SD) via cast method. The detailed procedure of preparation polyaniline, and adsorbent can be found in our previous report that we employed this adsorbent for removal of $\mathrm{Cr}(\mathrm{VI})$ ion from aqueous solutions ${ }^{19}$. The sawdust coated by PANi filtered and then dried at $\sim 60{ }^{\circ} \mathrm{C}$ in an oven for removing the remained solvent. Sawdust coated by polyaniline (PANi/SD) used for sorption of lead ion.

A glass column with dimensions of $1 \mathrm{~cm}$ diameter and $10 \mathrm{~cm}$ length equipped with a glass frit was employed as fixed packed bed for column adsorption experiments. A solution of $100 \mathrm{ppm}$ of lead ion in distilled water obtained from $\mathrm{Pb}\left(\mathrm{NO}_{3}\right)_{2}$ salt was used as synthetic polluted test solution. Lead ion solution for adsorption experiments and calibration curve preparation was prepared from a $\mathrm{Pb}\left(\mathrm{NO}_{3}\right)_{2}$. Quantitative determination of lead was carried out using atomic absorption spectroscopy (AAS). For concentrations below $10 \mathrm{ppm}$ wavelength of $217 \mathrm{~nm}$ and slit $10 \mathrm{~mm}$, for concentrations of 10-100 ppm the wavelength of $261.4 \mathrm{~nm}$ and slit $0.5 \mathrm{~mm}$ were used. The evaluation of the metal uptake was performed according to: $\mathrm{X}=\mathrm{V}\left(\mathrm{C}_{\mathrm{i}}-\mathrm{C}_{\mathrm{e}}\right) \mathrm{w}^{-1}$, where $\mathrm{V}$ is the volume of inlet solution, $\mathrm{C}_{\mathrm{i}}$ and $\mathrm{C}_{\mathrm{e}}$ are the inlet (initial) and outlet (unadsorbed) concentration respectively, and $\mathrm{w}$ is the dry weight of adsorbent.

\section{Results and Discussion}

(I) Adsorption studies using PANi (Batch system)

\section{(i) Effect of initial concentration}

For performing this experiment, $50 \mathrm{mg}$ polymer (PANi powder) was treated with $5 \mathrm{~mL}$ of 10 ppm $\mathrm{Pb}^{2+}$ for 30 minutes accompanied by shaking (200rpm). Unadsorbed lead was analyzed after separation the sorbent by centrifuge. The results obtained are shown in Figure 2. 


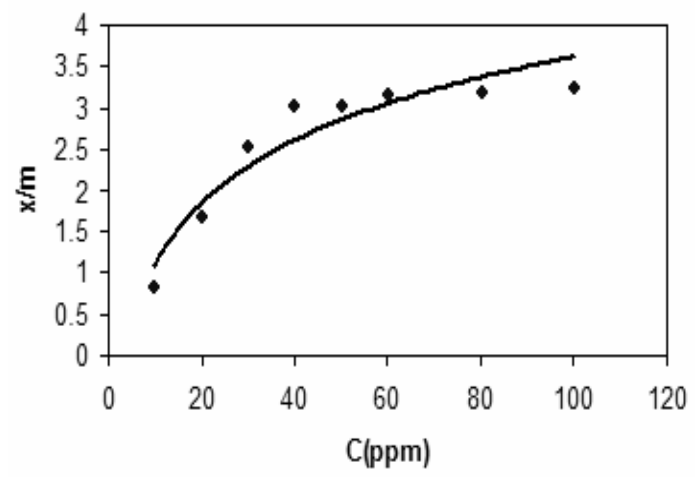

Figure 2. Effect of initial concentration on the removal of lead ion by PANi 52 R. ANSARI et al.

As the results show, increasing initial concentration of adsorbate $\left(\mathrm{Pb}^{2+}\right)$ leads to an increase in adsorption percent.

\section{(ii) Effect of sorbent dosage}

In this experiment different weights of adsorbent PANi (EB form) (0.10-1.0 g) were treated with $5.0 \mathrm{~mL}$ lead solutions with constant concentration of $100 \mathrm{ppm}$. All the other conditions were the same as used for Figure 2. The results obtained are shown in Figure 3.

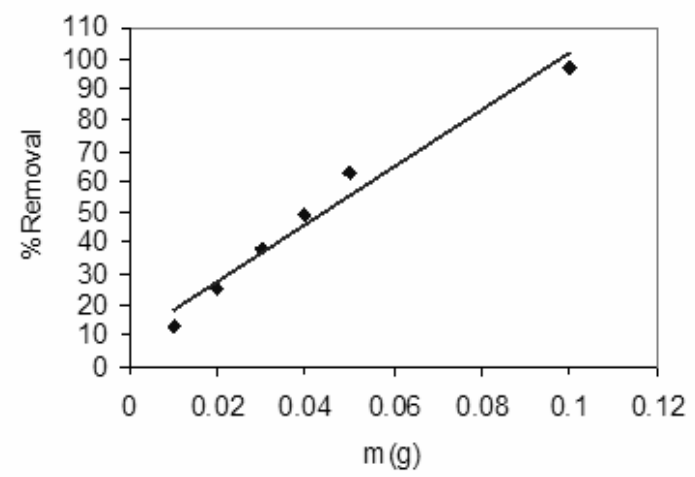

Figure 3. The effect of sorbent dosage (PANi) on $\mathrm{Pb}^{2+}$ sorption

As our results show, with increasing sorbent dosage (PANi), sorption percent increases. According to the results shown in Figure 3, $0.10 \mathrm{~g}$ of PANi/SD can completely clean $5 \mathrm{~mL}$ $100 \mathrm{ppm}$ aqueous solution contaminated by lead ion.

\section{(iii) Effect of pH}

For this investigation, $50 \mathrm{mg}$ of sorbent (PANi) were treated with $5 \mathrm{~mL}$ of $\mathrm{Pb}^{2+}$ ion $(50 \mathrm{ppm})$ at different $\mathrm{pH}$ values $(0-6)$. The $\mathrm{pH}$ of solutions was adjusted using dilute $\mathrm{HNO}_{3}$ solution $(0.1 \mathrm{M})$. The results obtained are shown in Figure 4. 


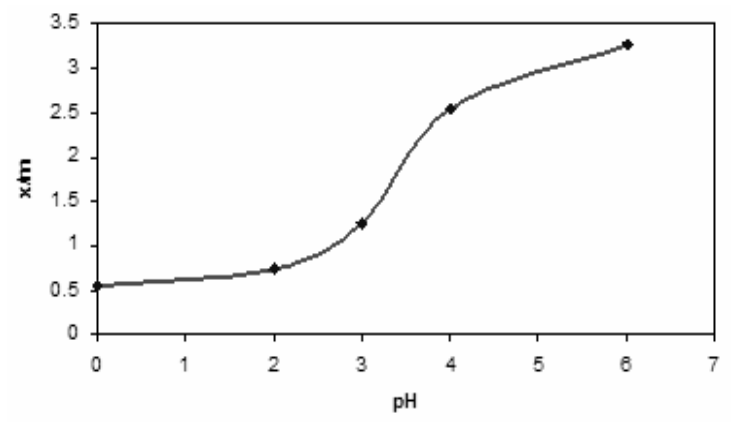

Figure 4. The effect of $\mathrm{pH}$ on $\mathrm{Pb}^{2+}$ sorption by PANi

As our results show, with increasing the $\mathrm{pH}$ of metal solution, sorption of lead ion is increased and in acidic media $(\mathrm{pH}<4)$ the sorption of metal ions is very poor. With increasing the $\mathrm{pH}$ of treated solution, the polymer is changed into undoped form, then free amine or imine groups in the polymer will be available for metal chelating, so the sorption of $\mathrm{Pb}^{2+}$ ion is increased considerably. At acidic $\mathrm{pH}$ values, polyaniline is changed into acid doped state ( $-\mathrm{N}$ groups are protonated), so the polymer can not function as a ligand or chelating agent, therefore, the metal uptake is not occurred.

Removal of Lead Ion from Aqueous Solutions

\section{(II) Adsorption Studies using PANi/SD sorbent (batch system)}

\section{(i) Effect of initial concentration}

For performing this experiment, $100 \mathrm{mg}$ adsorbent (PANi/SD) were treated with 10-100ppm lead ion solutions and the results are shown in Figure 5.

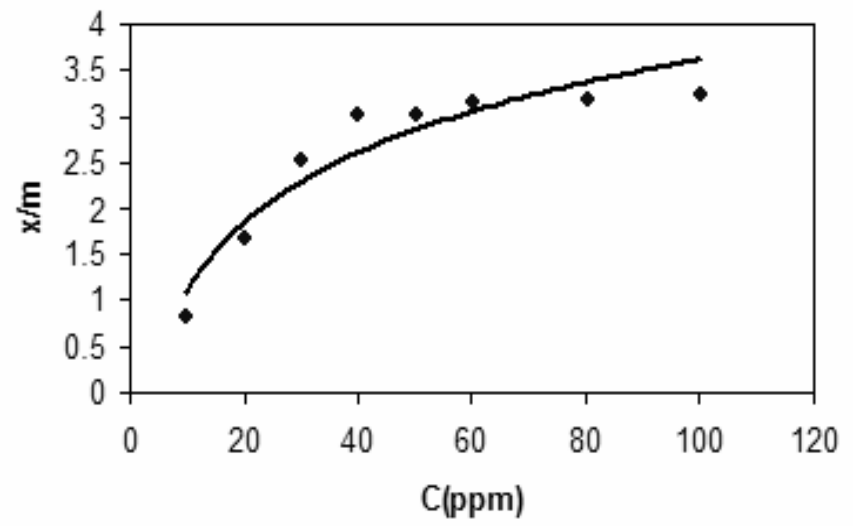

Figure 5. Effect of initial concentration on the removal of lead ion by PANi/SD. The adsorption experimental conditions and calculations were as described in Figure 2.

In order to have a better comparison, uncoated SD was also used for adsorption of lead ion and the results obtained were shown in Figure 6. 


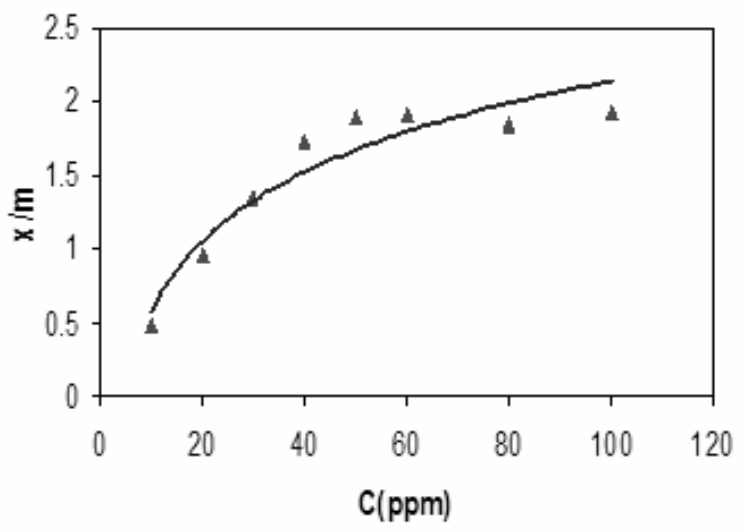

Figure 6. Effect of initial concentration on the removal of lead ion using sawdust (SD) as sorbent.

Our results indicate that the sorption of lead ion by both PANi/SD increases with increasing the initial concentration of metal ion. The lead ion can also be sorbed by SD but the sorption percent is much lower than PANi/SD.

\section{(ii) Effect of sorbent dosage}

For performing this research, $5.0 \mathrm{~mL}$ of $100 \mathrm{ppm}$ lead ion was treated with different weights of SD and PANi/SD sorbents with the same particle size (35-50 mesh). The results obtained are shown in Figure 7. As our results show (Figure 7), increasing sorbent dosage leads to complete elimination of lead ion from treated solution.

54 R. ANSARI et al.

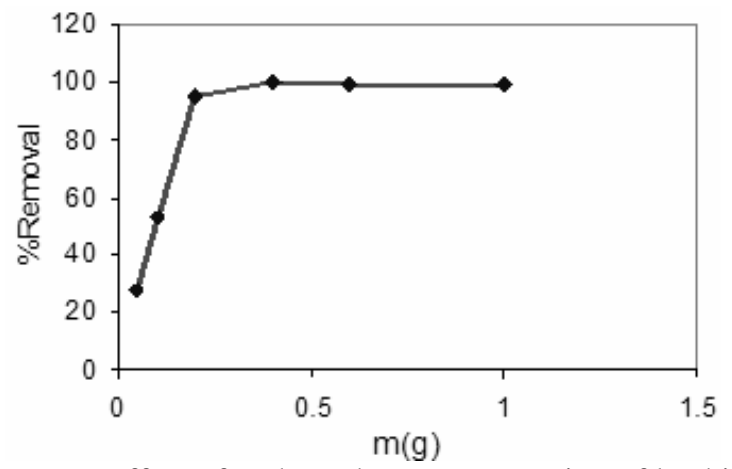

Figure 7 Effect of sorbent dosage on sorption of lead ion

\section{(iii) Effect of contact time}

For this investigation $0.10 \mathrm{~g}$ of PANiEB/SD or SD were mixed with $5 \mathrm{~mL}$ of $100 \mathrm{ppm}$ lead ion at different exposure times(5-120 min). The samples after filtration were analyzed for unadsorbed lead ion. The results are summarized in Figure 8. As it is indicated, sorption of metal ion is increased by increasing exposure time. 


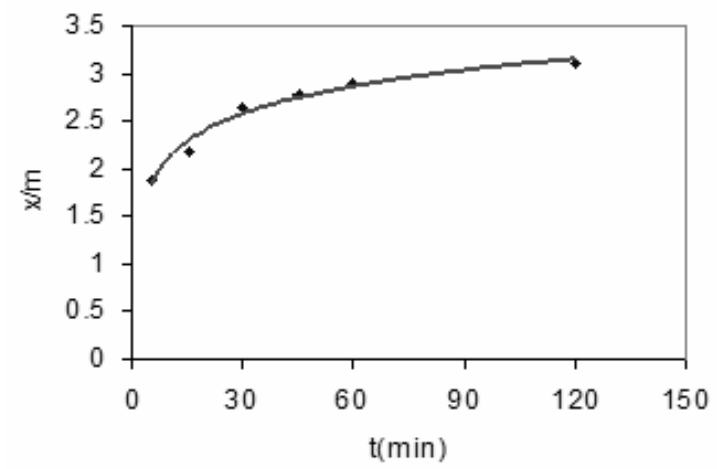

Figure 8. Effect of exposure time on lead sorption or removal by SD and PANiEB/SD

\section{(iii) Effect of agitation}

For this investigation $0.10 \mathrm{~g}$ of PANiEB/SD or SD were mixed with $5 \mathrm{~mL}$ of $100 \mathrm{ppm}$ lead ion for constant exposure time $(30 \mathrm{~min})$ at different rates of shaking $(0-250 \mathrm{rpm})$. The samples after filtration were analysed for unadsorbed lead ion. The results are summarized in Figure 9.

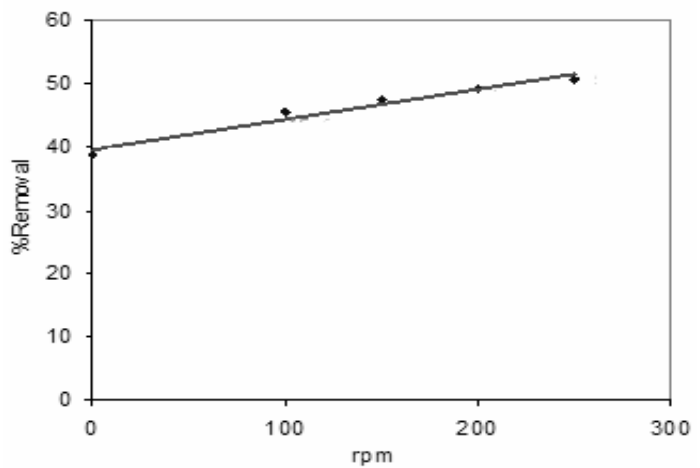

Figure 9. Effect of agitation rate on $\mathrm{Pb}^{2+}$ sorption $\mathrm{PANi} / \mathrm{SD}$

Removal of Lead Ion from Aqueous Solutions

As it is demonstrated, lead ion uptake by PANi/SD is improved by increasing the rate of agitation.

\section{(v) Effect of $\mathbf{p H}$}

For this investigation $0.10 \mathrm{~g}$ of $\mathrm{PANi} / \mathrm{SD}$ or $\mathrm{SD}$ were mixed with $5 \mathrm{~mL}$ of $50 \mathrm{ppm}$ lead ion for $30 \mathrm{~min}$ at different $\mathrm{pH}$ values using dilute $\mathrm{HNO}_{3}$. The samples were also agitated with the rate of 200rpm during exposure. Then, the samples were filtered and analysed for unadsorbed lead ion. The results are summarized in Figure 10. 


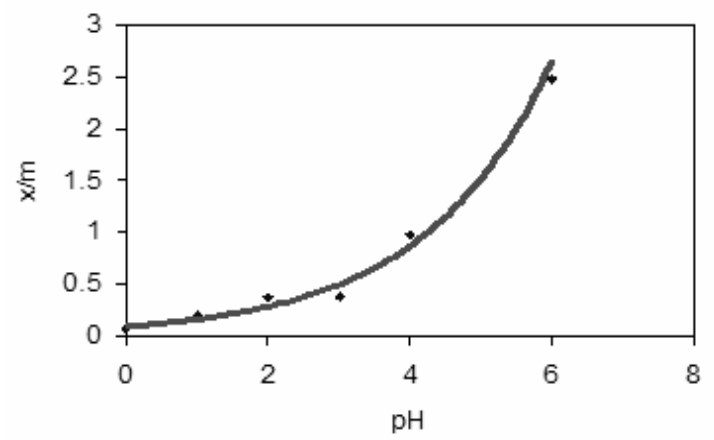

Figure 10. Effect of $\mathrm{pH}$ on lead sorption by PANi/SD

As we have already observed in the case of pure PANi, higher lead ion sorption is observed for PANi/SD at higher $\mathrm{pH}$ values too.

\section{(vi) Desorption study}

When a solid sorbent is applied for sorption of pollutants (organics or inorganics), the possibility of regeneration of the sorbent is a great importance from the point of application view in industries. However; complete regeneration is not always possible. In this research for desorption study, $0.10 \mathrm{~g}$ of PANi/SD was first treated with $5.0 \mathrm{~mL}$ of $100 \mathrm{ppm}$ lead ion in distilled water for $30 \mathrm{~min}$. For regeneration of the sorbent or recovery of lead ion, sorbent containing lead ion were treated with $5 \mathrm{~mL}$ of $\mathrm{HNO}_{3} 0.5 \mathrm{M}$ at RT. The results obtained (sorption and desorption) are shown in Table 1.

Table 1 Regeneration of exhausted PANi/SD sorbent

\begin{tabular}{cccc}
\hline $\begin{array}{c}\text { PANi/SD } \\
\text { g (weight) }\end{array}$ & $\begin{array}{c}\text { \%Regenration } \\
\text { with } 5 \text { mL H }\end{array}$ & \%Removal & $\begin{array}{c}\text { \%Regenration } \\
\text { With 5 } \mathrm{mL} \mathrm{HNO}_{3}\end{array}$ \\
\hline 0.10 & $\sim 0$ & 52 & 68 \\
0.10 & $\sim 0$ & 50 & 73 \\
0.10 & $\sim 0$ & 50.5 & 84.5 \\
0.10 & $\sim 0$ & 49 & 82.5 \\
0.10 & $\sim 0$ & 51 & 74.0 \\
\hline
\end{tabular}

Simple washing with distilled water can not remove the sorbed metal ions. Employing $\mathrm{HNO}_{3}$ as a regenerant solution, it is possible to regenerate the used adsorbent up to 70-75 percent.

\section{(vii) Sorption of lead ion using Regenerated PANi/SD}

In order to performing this experiment, $0.10 \mathrm{~g}$ of regenerated PANi/SD was treated with 5 $\mathrm{mL}$ of $50 \mathrm{ppm}$ lead ion prepared in distilled water and then agitated with 200rpm for 30 minutes. It was observed that the regenerated sorbent can effectively adsorb lead ion without any important loss in its sorption capacity compared to unused state (Table 2). The loss in sorption capacity was about $2 \%$.

56 R. ANSARI et al.

Table 2 Sorption of lead ion by regenerated PANi/SD sorbent.

\begin{tabular}{|c|c|c|c|c|c|}
\hline PANiEB/SD $\mathrm{g}$ & $\mathrm{C}(\mathrm{ppm})$ & $\mathrm{V}(\mathrm{ml})$ & $\mathrm{rpm}$ & Time (min) & $\%$ Removal \\
\hline 0.1 & 50 & 5 & 200 & 30 & $\% 97.5$ \\
\hline 0.1 & 50 & 5 & 200 & 30 & $\% 96.4$ \\
\hline 0.1 & 50 & 5 & 200 & 30 & $\% 98.2$ \\
\hline
\end{tabular}




\begin{tabular}{llllll}
\hline 0.1 & 50 & 5 & 200 & 30 & $\% 97.8$ \\
\hline
\end{tabular}

\section{(III) Adsorption studies using PANi/SD sorbent (Column systems)}

Parameters obtained in batch processes are useful in providing information for continuous or column systems that are more practical in industries for treatment systems. However the data obtained in batch experiments are generally not valid for continuous flow systems. It is therefore, necessary to perform flow test using column in the assessment of the usefulness of a system in real applications. It is also needed to mention that polyaniline is finely divided or powdered form and can not be used in column system because of resulting important pressure drop of the liquid passed through the column. Therefore, column system was used for PANi/SD as sorbent, but for batch investigation both PANi or EB and PANi/SD was employed.

\section{(i) Effect of initial concentration of $\mathrm{Pb}^{2+}$ ion}

In this experiment, $1.0 \mathrm{~g}$ of sorbent $(\mathrm{PANi} / \mathrm{SD})$ packed in a glass column $(1 \mathrm{~cm} \times 10 \mathrm{~cm}$ dimensions). The column was first washed with $0.1 \mathrm{M} \mathrm{HCl}$ and $0.5 \mathrm{M}$ ammonia solutions separately. The column was finally washed with distilled water. Then, $10 \mathrm{~mL}$ of lead ion solution with different initial concentrations (10-100 ppm) passed through the column with flow rate of $3 \mathrm{~mL} / \mathrm{min}$ at room temperature. The results obtained are shown in Figure 11.

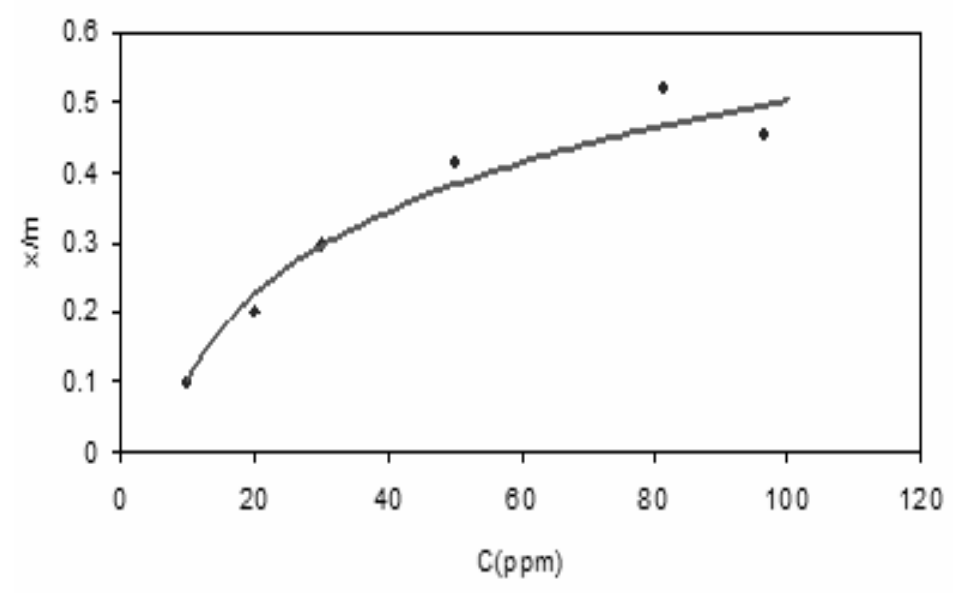

Figure 11. Effect of initial $\mathrm{Pb}^{2+}$ ion concentration on sorption by PANi/SD column.

\section{(iii) Effect of flow rate}

In this part of investigation, $50 \mathrm{~mL}$ of lead ion with concentration of $100 \mathrm{ppm}$ passed through the column containing $1.0 \mathrm{~g}$ PANi/SD sorbent with different flow rates $(1-5 \mathrm{~mL}$ $\left.\mathrm{min}^{-1}\right)$. The results are summarized in Figure 12 . 


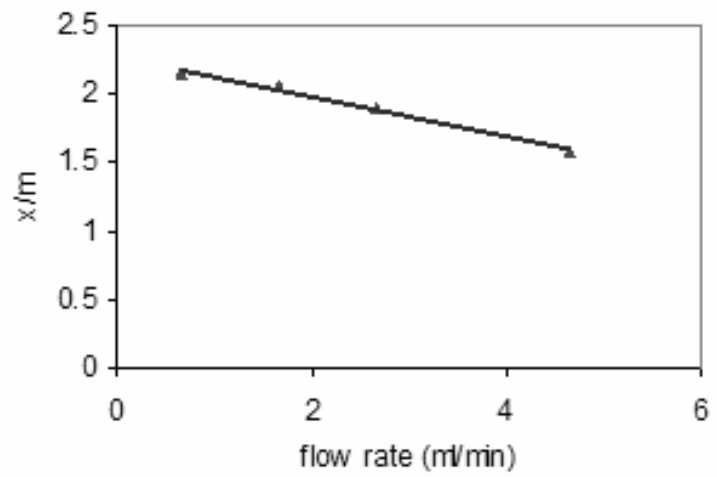

Figure 12. Effect of flow rate on sorption of lead ion by PANi/SD column

According to the results obtained, it can be concluded that increasing flow rate of liquid through the column, \% sorption decreases. Efficient removal of lead ion can be achieved at low flow rates of solutions in column system.

\section{(iv) Effect of pH}

In order to investigate the effect of $\mathrm{pH}$ on sorption of $\mathrm{Pb}^{2+}$ ion by PANi/SD column, $1.0 \mathrm{~g}$ of sorbent packed in glass column as described before. $50 \mathrm{~mL}$ of $\mathrm{Pb}^{2+}$ solution $(100 \mathrm{ppm})$ at different $\mathrm{pH}$ (from 0 to 6 using $\mathrm{HCl}$ ) passed through the column with flow rate of $3 \mathrm{ml} / \mathrm{min}$ at RT. The results obtained are shown in Figure 13.

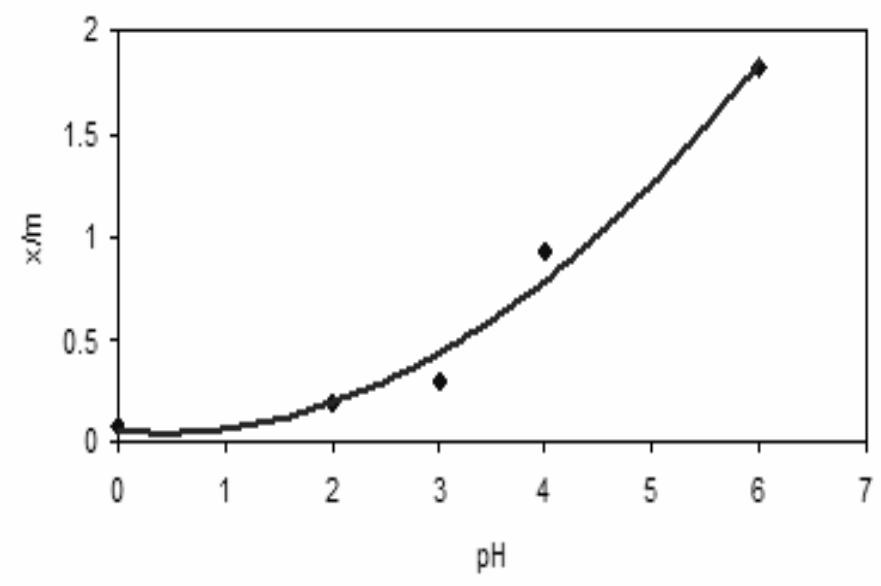

Figure 13. Effect of $\mathrm{pH}$ on $\mathrm{Pb}^{2+}$ sorption by $\mathrm{PANi} / \mathrm{SD}$ column

As our results show, sorption of $\mathrm{Pb}^{2+}$ ion increases as $\mathrm{pH}$ of treated solution increases. However at higher $\mathrm{pH}$ values (alkaline), precipitation of $\mathrm{Pb}^{2+}$ ions may occur as well. The same finding was obtained in our batch system investigation.

\section{(v) Breakthrough curves for SD and PANi/SD sorbents}

In this experiment, $1.0 \mathrm{~g}$ of PANi/SD packed in a glass column, and then $\mathrm{Pb}^{2+}$ solution with concentration of $50 \mathrm{ppm}$ passed through the column with constant flow rate $\left(3 \mathrm{~mL} \mathrm{~min}^{-1}\right)$. Each time $10 \mathrm{ml}$ was poured into the column. The outlet solution was analyzed for unadsorbed $\mathrm{Pb}^{2+}$ ion in order to obtain the break through curve. The results obtained are shown in Figure 14.

58 R. ANSARI et al. 


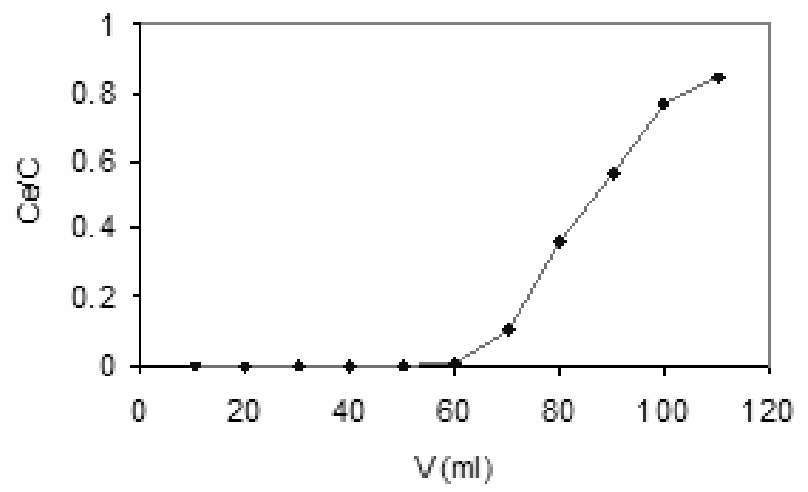

Figure 14. Breakthrough curves obtained for adsorption of lead ion by PANi/SD column.

As the results show (Figure 14), our recent developed adsorbent can be used effectively in contineous or column systems. $60 \mathrm{~mL}$ of meccuric solution with concentration of $50 \mathrm{ppm}$ can be completely purified by the column containing $1.0 \mathrm{~g}$ PANi/SD sorbent.

\section{(vi) Desorption study}

For performing this investigation, $10 \mathrm{mg}$ of adsorbent (PANi /SD) was first treated with $5 \mathrm{ml}$ of $\mathrm{Pb}^{2+}$ with concentration $100 \mathrm{ppm}$ (sorption was \%50). The exhausted column was then treated with $0.5 \mathrm{M} \mathrm{HCl}$ solution for 5 minutes for regeneration. The analysis showed that 60 - \% 65 of the sorbed metal (lead ion) could be recovered. Increasing exposure time or concentration of regenerant $(\mathrm{HCl})$, recovery percent might be improved. It should also be remembered that biomaterials (e.g. SD) are not very stable in strong acidic or basic conditions. Therefore; application strong acidic or basic media should be avoided when we work with biomaterials.

\section{Conclusion}

Polyaniline can be easily synthesized chemically directly on sawdust or coated via cast method. Sawdust which is a very cheap and environmental friendly material was found to be a suitable substrate for coating of PANi in order to be used in water and wastewater treatments for removal of heavy metal ions from solutions both for batch and column systems. Sorption or metal uptake by our recently developed sorbent seems to be occurred mostly via complex formation reaction or chelating between metal ion and amine groups in polymer (PANi). In acidic media the amine groups are protonated, so desorption of metal ion is occurred. Under neutral conditions, PANi exists in deprotonated form, so the free $-\mathrm{N}$ groups will be available for metal chelating. Sorption/desorption of lead ions by PANi, is mostly reversible and the processes can be simply controlled by $\mathrm{pH}$ of solution. The finding in this paper is very important from application point of view for water and wastewater treatments in order to remove toxic heavy metal ions.

\section{References}

1. Tramontina J, Marchado G, Azambuja D S, Piatnicki C M S and Samios D, Material Research, 2001,4, 195.

2. Rengaraj S, Kyeong-Ho Yeon, Seung-Hyeon Moon, Journal of hazard. Mater., 2001, B87, 273.

3. Gomez Serrano V, Garcia A M and Mansilla A E, Journal of Water Res.,1998, 321. 
4. Bansode R, Losso J N, Marshall W E and Rao R M, Biosource technology, 2003, 89, 115.

5. Kadirvelu K, Thamaraiselvi K and Namasivayam C, Biosource Technology, 2001,76, 63.

6. Anoop Kapoor, Viraraghavan T and Roy Cullimore D, Biosource Technology, 1999,70, 95.

7. Weidlich C, Mangold K M and Juttner K, Electrochimica Acta, 2001, 47, 741.

8. Ansari R and Omidvari R, Polish Journal of Environmental Studies, 2005,14,191.

9. Zeng X. R. and Man Ko T., Polymer, 1998, 39, 1187.

10. Gospondinova N and Terlemezyan, Prog. Polym. Science, 1998, 23,1443.

11. Kang E T, Neoh K G and Tan K L, Prog. Polym. Science, 1998,23, 277.

12. Negi Y S and Adhyapak, J. Macromol. Sci. Polym. Rev., 2002,C 42, 35.

13. Hung W S, Humphrey B D and Mac Diarmid A G, Chem. Soc. Farad. Trans., 1986, 82, 2385.

14. Cao Y, Andreatta A, Heeger A J and Smith P, Polymer, 1989, 30, 2305.

15. Chiang J C and MacDiarmid A G, Synthetic Metals, 1989, 13, 193.

16. Focke W W, Wnek G E, and Wei Y, J. of Physical Chemistry and references therein, 1987, 91, 5813.

17. Gurunathan K, Murugan A. V, Marimuthu R, Mulik U P and Amalnerkar D P, Material Chemistry and Physics, 1999, 61, 173.

18. Foot P J and Simon R, J. Phys. D: Appl. Phys., 1989, 22, 1598.

19. Ansari R, Aliakbar A and Masoudi M, Journal Polymer Materials, 2005, 2, 75. 


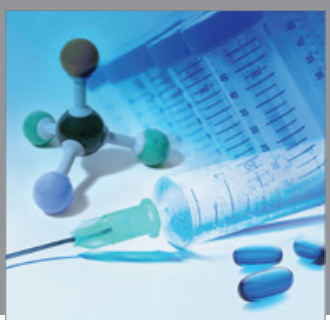

International Journal of

Medicinal Chemistry

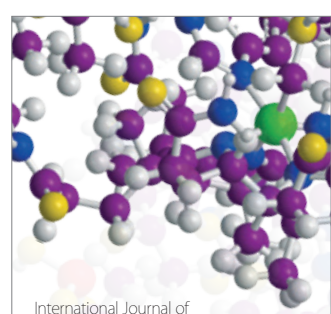

Carbohydrate Chemistry

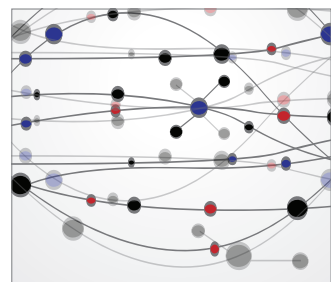

The Scientific World Journal
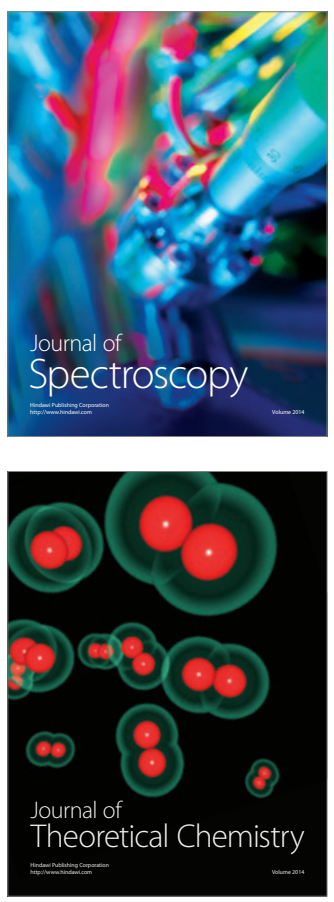
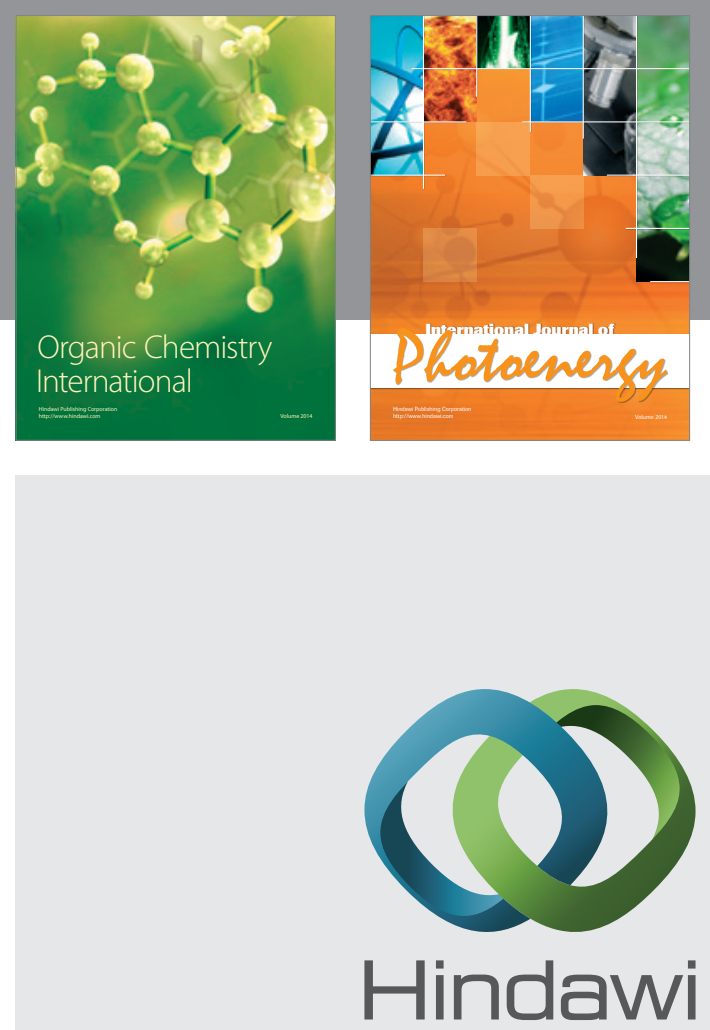

Submit your manuscripts at

http://www.hindawi.com
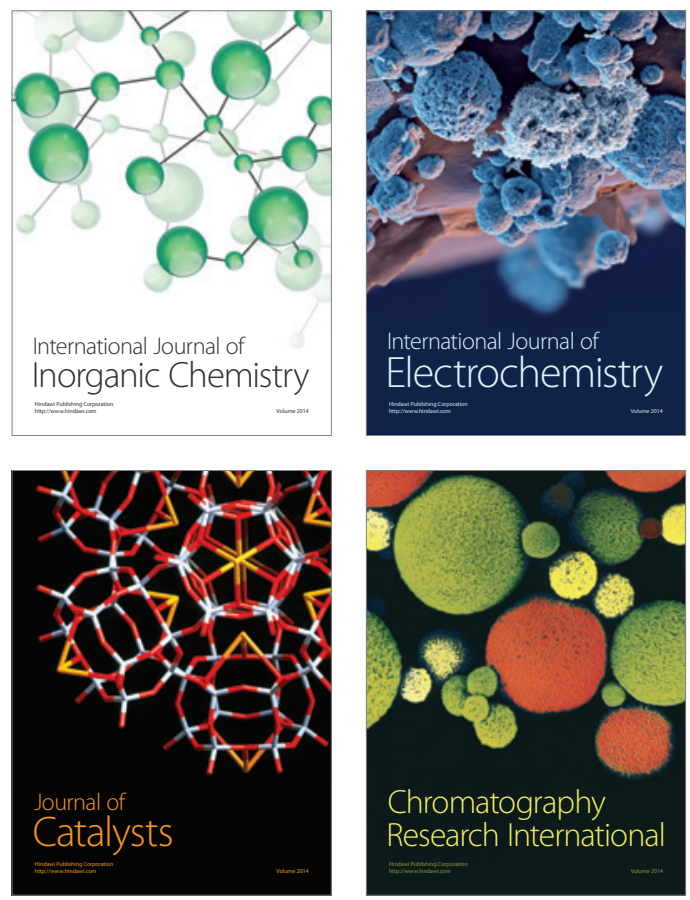
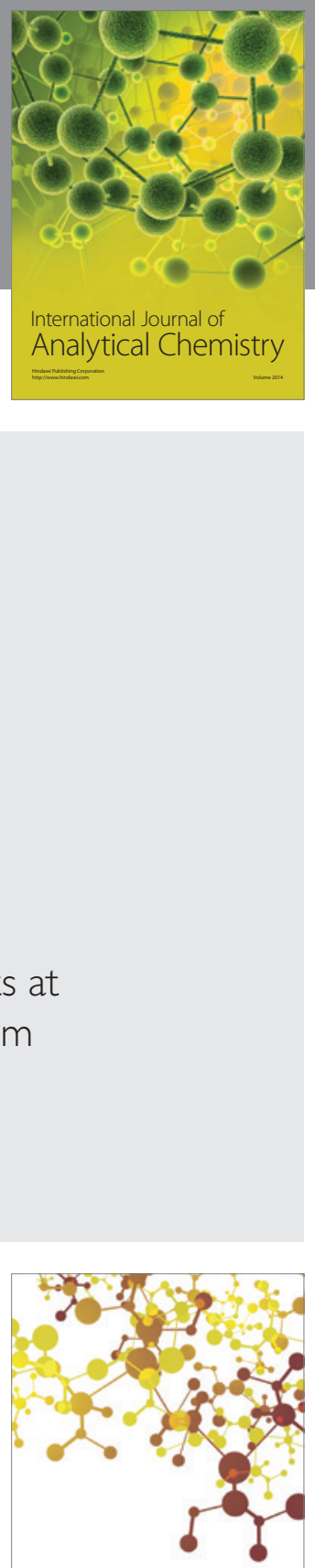

Journal of

Applied Chemistry
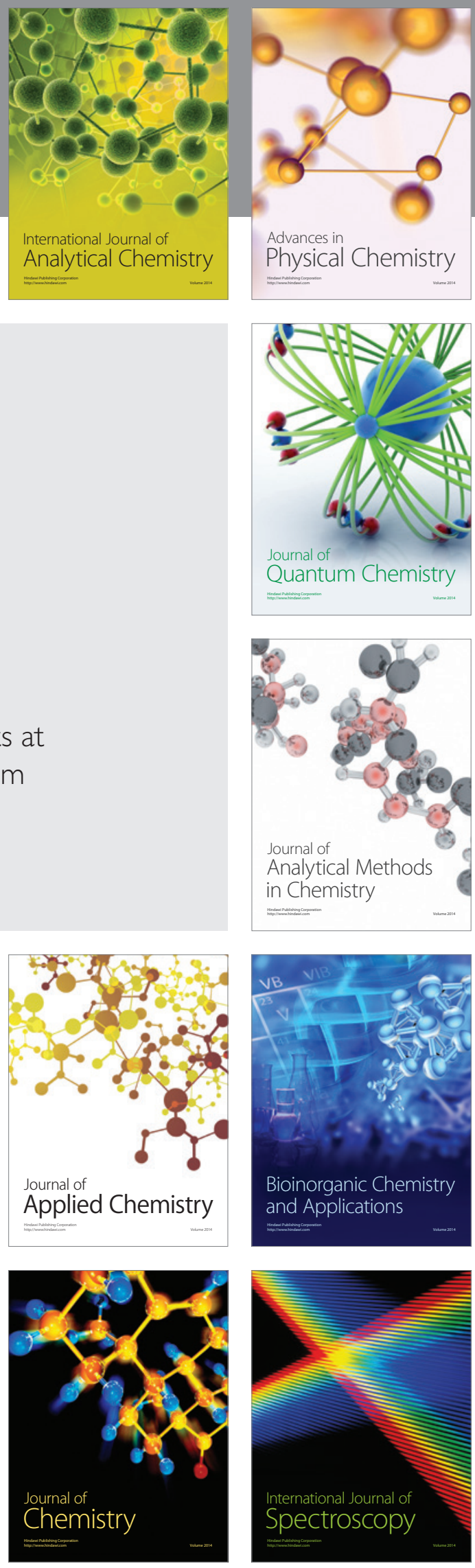